\title{
Enhanced Toughness of Reed (Phragmites australis) Stalk with Polyethylene Glycol
}

\author{
Xue Zhao, ${ }^{\mathrm{a}}$ Mingjie Wang, ${ }^{\mathrm{a}}$ Kai Shang, ${ }^{\mathrm{b}}$ Yao Chen, ${ }^{\mathrm{a}, *}$ and Jianmin Gao ${ }^{\mathrm{a}, *}$
}

Reed (Phragmites australis) is a cosmopolitan grass that is often the dominant species in the ecosystems it inhabits. It is widely used in furniture decoration as reed weaving products. However, the application of reed is limited due to its brittle nature and susceptibility to cracks. To increase the toughness of reed stalk, sodium chlorite $\left(\mathrm{NaClO}_{2}\right)$ was used to remove the lignin from reed stalk, and then polyethylene glycol with different molecular weights (PEG 600, PEG 1000, PEG 2000, and PEG 4000) was used as a plasticizer. The micromorphology, crystal structure, and surface chemical composition of the modified reed stalk were characterized by scanning electron microscopy (SEM), X-ray diffraction (XRD), and Fourier transform infrared spectroscopy (FT-IR). The bending strength and dynamic thermomechanical analysis (DMA) of the reed stalk were evaluated. The results showed that the delignified reed stalks plasticized with PEG 1000 or PEG 2000 showed better dimensional stability and toughness, and the smallest elastic modulus (133.268 MPa) was obtained when the samples were treated with PEG 2000. The results of thickness swelling showed that the dimensional stability increased after PEG modification. This research may provide the theoretical basis for the modification of reed stalk.

Keywords: Reed stalk; Polyethylene glycol (PEG); Toughness; Mechanical properties

Contact information: a: MOE Key Laboratory of Wooden Materials Science and Application, College of Materials Science and Technology, Beijing Forestry University, Beijing, 100083, China; b: Shandong Jiaotong University, Jinan, Shandong, 250357, China

*Corresponding author: ychen@bjfu.edu.cn;jmgao@bjfu.edu.cn

\section{INTRODUCTION}

Reed (Phragmites australis) is a perennial herb found in wetlands throughout temperate and tropical regions of the world. Reed occurs along the margins of lakes, fens, marshes, and streams from the Arctic to the tropics. It is a broad-leafed grass, about 1.5 to $5 \mathrm{~m}$ (5 to 16.5 feet) tall, with feathery flower clusters and stiff, smooth stems. Dried reed stems have been used for thousands of years as thatching and construction material, in basketry, for arrows and pens, and in musical instruments. They also are harvested for their cellulose content. Phragmites has been used widely in the papermaking and fiberboard industries on account of its widely dispersed nature. In modern home life, phragmites have been used for weaving supplies such as furniture surface decorations, mats, straw baskets, fishing gear, etc. However, the brittleness of reed stalk causes it to easily break due to weather, external forces, and other factors during the manufacturing process, which restricts its further application in weaving products. The chemical composition and physical properties of reed have been studied by many researchers. It was reported that the hollow structure and the developed microscopic voids are responsible for the brittleness under external forces. This is a practical problem that must be solved to improve the 
toughness of reed stalk and expand its applications.

Few studies have been reported on the toughness improvement of straw. However, crop straw varieties have been widely used in composite processing, taking advantage of their favorable characteristics. Wheat straw was used to reinforce polypropylene (PP) to make a lightweight composite. It was found that the bending strength, elastic modulus, impact strength, and other parameters of the material increased. Wheat straw material can be an ideal reinforcement for improving mechanical properties of polymer (Zou et al. 2010). Polystyrene (PS) and polyvinyl alcohol (PVOH) were used to modify rice straw fibers (RSF). It was reported that the bending strength, impact strength, and elastic modulus of the composites increased with the increase in the percentage of PS or PVOH. The physical properties of the composites varied with the content of the straw fiber (Ismail et al. 2011). African teff straw (Eragrostis tef) has been reinforced with epoxy using a simple hand layup technique with different fiber loadings ranging from $5 \%$ to $25 \%$. The fiber surface was treated with 5\% alkali, $10 \%$ alkali, silane, and acetic anhydride to improve the interaction combination between fiber and matrix. It was reported that the tensile strength and flexural strength increased $40 \%$ and $25 \%$, respectively, with $15 \%$ fiber loading and silane treatment. The combination of the straw fiber and the matrix can be improved by pretreatment (Devnani and Sinha 2019). It was reported that wheat straw fibers were treated with alkali $(1 \%, 3 \%$, and $5 \%)$ and then reinforced with epoxy resin. The treatment with alkali showed positive effects on improving the mechanical properties of the composites (Mittal and Sinha 2017). Pineapple leaf fibers (PALFs) were popularly used for its high fiber content (80\%). It was reported that the PALFs/epoxy resin composites with 10\% fiber loading showed better mechanical properties (Jain et al. 2019). Straw fibers have been mostly used as reinforcement of polymer matrix. It would be great value if these materials could be used in weaving products on furniture and decoration field. Currently, there have been few studies focused on improving mechanical properties of the straw materials. However, the studies cited above have provided reference for modification of the straw materials.

Polyethylene glycol (PEG) has been used widely in wood modification due to its excellent swelling properties and non-polluting characteristics (Stamm 1964; Yamaguchi et al. 1999). PEG has received much attention for its wood antiseptic property and dimensional stability improvement in recent years. It was reported that PEG reagents with three different molecular weights were impregnated into oak wood; the absorption of PEG in the wood was improved significantly when negative pressure was employed for impregnation (Stamm and Tarkow 1947; Bjurhager et al. 2010; Chaouch et al. 2010; Hamada et al. 2016; Meints et al. 2018).

Up to this point, many researchers have studied the mechanical properties of biomass stalks, such as wheat, rice, sugarcane, etc., which have promoted the accurate determination of the mechanical properties of related crops. The present study aims to increase the toughness strength of the reed stalk. The reed stalk was treated using sodium chlorite $\left(\mathrm{NaClO}_{2}\right)$ to partially remove lignin, and then it was reinforced with polyethylene glycols with different molecular weights (PEG 600, PEG 1000, PEG 2000, and PEG 4000). The negative pressure impregnation method was employed. The micromorphology and chemical structures of the reed stalk were investigated using scanning electron microscopy (SEM), X-ray diffraction (XRD), and Fourier transform infrared spectroscopy (FT-IR). The bending strength and mechanical properties were analyzed. Dynamic mechanical analysis (DMA) reveals the obtained strain (or stress) to the response of stress (or strain) 
under certain test conditions (temperature, humidity, load frequency, and stress or strain level), which is analyzed via the structure and the molecular motion of materials (Rials and Glasser 1984; Jacob et al. 2006; Havimo 2009; Engelund and Salmen 2012; Kaboorani and Blanchet 2014; Hazarika et al. 2014; Jin et al. 2016).

\section{EXPERIMENTAL}

\section{Materials}

Preparation of raw material

The reed was collected from the Beijing Yeya Lake Wetland Nature Reserve (Beijing, China). The stalk accounted for the biggest proportion of reed structure $(62.9 \%)$, followed by root at $26.5 \%$, and the remainder was made up by the tip (10.6\%). The reed stalk was selected as the research object in this study. The mechanical strength around the reed nodes was stronger than other sections. In order to avoid this inequality in the mechanical performance test, the stalks were divided into $9-\mathrm{cm}$ to $16-\mathrm{cm}-$ long segments, avoiding the nodes. The samples without defects and with diameters of approximately 5 $\mathrm{mm}$ were selected. Five similar samples were selected as replicates. Five groups (a total of 25) samples were used in this study.

\section{Reagents}

Sodium chlorite $\left(\mathrm{NaClO}_{2}\right)$, acetic acid $\left(\mathrm{CH}_{3} \mathrm{COOH}\right)$, anhydrous ethanol, and polyethylene glycol (PEG 600, PEG 1000, PEG 2000, and PEG 4000) were used as the analytical reagents. All the above reagents were produced by Sinopharm Chemical Reagent Co., Ltd., Beijing, China.

\section{Methods}

Delignification of the reed stalks

The lignin in the reed stalks was partly removed using an acid sodium chlorite aqueous solution, as described in a previous study (Ahlgren and Goring 2011). $\mathrm{NaClO}_{2}$ was dissolved in deionized water at a weight ratio of 1:50 and $\mathrm{CH}_{3} \mathrm{COOH}$ was introduced to adjust the $\mathrm{pH}$ to 4 . Reed stalks were immersed in the solution and heated at $80{ }^{\circ} \mathrm{C}$ for 2 $\mathrm{h}$ to partly remove the lignin.

\section{Modification of the delignified samples with PEG}

Deionized water, PEG (PEG 600, PEG 1000, PEG 2000, and PEG 4000), and anhydrous ethanol were mixed at a weight ratio of 6:3:1. The delignified reed stalks were immersed in the PEG modifier and placed under vacuum conditions for $24 \mathrm{~h}$ under a negative pressure of $-0.09 \mathrm{MPa}$. After that, the samples were dried and sealed in plastic bags.

\section{Scanning electron microscopy}

The micromorphology of the inner/outer surface and cross-section of the reed samples under different conditions (untreated, delignified, and modified with different PEG) were studied by SEM (Model S-3400N II; Hitachi, Chiyoda City, Tokyo, Japan). The structural transition of the vessels and distribution of the PEG modifier were discussed in detail. 


\section{Fourier transform infrared}

FT-IR spectra were used to analyze the functional group changes of all samples. The measurement was conducted on a VERTEX 70v (Bruker Optics, Billerica, Massachusetts, USA) using the attenuated total reflectance (ATR) tableting method, and the measurement range was $500 \mathrm{~cm}^{-1}$ to $4000 \mathrm{~cm}^{-1}$.

\section{$X$-Ray diffraction}

Untreated, delignified, and different PEG-modified reed samples were evaluated by XRD (D8-Advance; Bruker AXS Inc., Madison, Wisconsin, USA), using Cu-K $\alpha$ radiation with a $2 \underline{\theta}$ range of $5^{\circ}$ to $60^{\circ}$ at a speed of $4 \% \mathrm{~min}$, to determine their phase composition. The crystallinity of the cellulose in reed fiber was then calculated based on XRD patterns, according to Eq. 1 (Segal et al. 1959),

$$
\operatorname{CrI}=\frac{I_{0.02}-I_{a m}}{I_{0.02}}
$$

where $I_{0.02}$ is the peak intensity of the crystalline plane (002) of the cellulose crystalline region and $I_{\mathrm{am}}$ is the peak intensity of the amorphous region.

\section{Bending test}

The modified reed stalks were numbered, and the diameter and wall thickness of each sample was measured. The following method for straw diameter and wall thickness measurement was employed in this study. The two ends of the reed section were selected as the measurement points, and the average value was calculated. A three-point bending method was used to conduct a stalk bending test on a microcomputer-controlled electronic universal testing machine (MMW-5; Naier, Jinan, Shandong, China). Five samples were used as a repeated group for testing. A horizontal curved metal frame was used to support both ends of the sample, and the gauge distance was $6 \mathrm{~cm}$. A microcomputer-controlled upper chuck was used to load the sample laterally at the midpoint of the length of the sample, the loading speed was $5 \mathrm{~mm} / \mathrm{min}$, and data were collected by a computer stress sensor. The test was stopped after the sample produced the maximum load. The stalk thickness was measured, and the moment of inertia (I) was obtained by using Eq. 3. The bending deflection was selected at the final point of the maximum load section. During the test, the creep phenomenon was prone to occur at the end of the maximum load, so it interfered with the selection of the bending deflection. The experiments uniformly selected the amount of deformation before creep as the bending deflection.

The three-point bending method of the elastic modulus $E$ of the stalk was calculated using Eq. 2,

$$
E=\frac{F l^{3}}{48 y I}
$$

where $F$ is the load in span $(\mathrm{N}), l$ is the scale moment $(\mathrm{mm})$, that is, the distance between two pivot points, $y$ is the bend deflection $(\mathrm{mm})$ at the midpoint of the test piece, $I$ is the moment of inertia of the cross-section to the neutral axis $(\mathrm{mm})$, the cross-section of the reed stalk can be approximated as a circular ring.

The expression of its moment of inertia I is shown in Eq. 3,

$$
I=\frac{\pi\left[D^{4}-(D-2 t)^{4}\right]}{64}
$$


where $D$ is the average outer diameter $(\mathrm{mm})$ of the stalk and $t$ is the wall thickness $(\mathrm{mm})$ of the stalk.

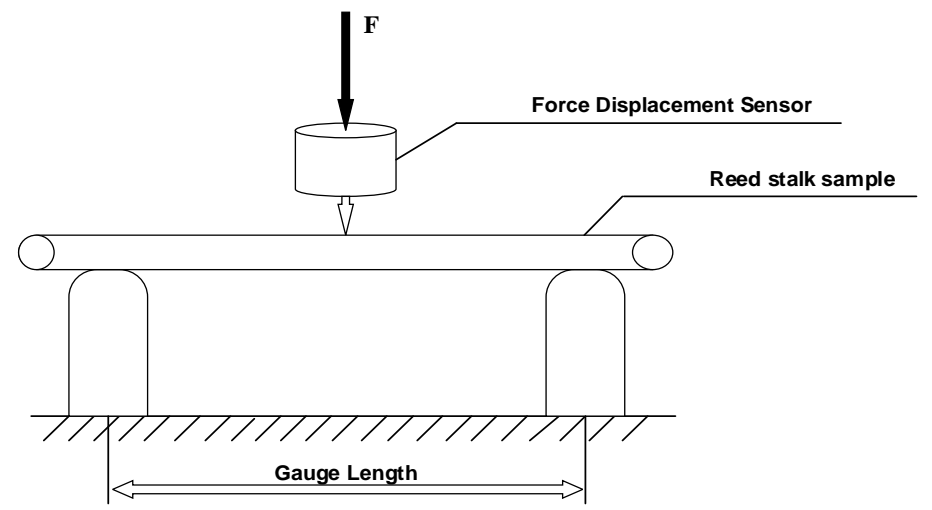

Fig. 1. Sketch of three-point bending experiment

\section{Thickness swelling}

PEG was used to modify the cell wall so that a large number of free hydroxyl groups were introduced. The physical properties of the reed could be modified after PEG modification. As a result of the modification the expansion rate of water absorption thickness will change accordingly. The thickness swelling of the modified reeds stalk was measured according to "GBT 17657-2013 wood-based panels and finishes Test Method for physical and chemical Properties of wood-based panel". The samples tested for moisture resistance were cut into pieces of $30 \mathrm{~mm} \times 10 \mathrm{~mm}$. The samples were oven-dried for $12 \mathrm{~h}$ at $105{ }^{\circ} \mathrm{C}$. The weight and thickness of these samples were determined before soaking in distilled water at room temperature. For each treatment, five replicates were weighted, and five different spots on each specimen were measured for thickness. The specimen was placed in a test tube and immersed in distilled water at room temperature. The samples were weighted after $24 \mathrm{~h}$ of soaking, and weight every $2 \mathrm{~h}$ until the weight difference was less than $0.1 \%$ of the sample weight.

The thickness swelling $T$ at the measurement point of each specimen was calculated according to Eq. 4,

$$
T=\frac{T_{2}-T_{1}}{T_{1}} * 100
$$

where $T$ is thickness swelling (\%), $T_{l}$ is thickness ( $\left.\mathrm{mm}\right)$ of sample before water soaking and $T_{2}$ is the sample thickness ( $\left.\mathrm{mm}\right)$ after water soaking.

\section{Dynamic mechanical analysis}

Dynamic mechanical analysis (DMA) is a method to detect the obtained strain (or stress) to the response of the stress (or strain) under certain test conditions (temperature, humidity, load frequency, stress or strain level). DMA is widely used in the field of viscoelasticity of polymer materials (Jacob et al. 2006; Havimo 2009; Hazarika et al. 2014; Jin et al. 2016). As a type of biomass polymer material, reed has viscoelastic properties. The mechanical properties of reed are essentially a reflection of the state of molecular movement. The DMA test was performed on a DMA-Q800 (TA Instruments, new castle, Delaware, USA) dynamic mechanics analyzer at a frequency of $50 \mathrm{~Hz}$. The dynamic storage modulus, loss modulus, and loss angle of the reed stalk sample were reported at a temperature range of $-20{ }^{\circ} \mathrm{C}$ to $260{ }^{\circ} \mathrm{C}$ with a heating rate $1 \mathrm{~mm} / \mathrm{min}$. To ensure the 
feasibility of the test, the same tightening force was applied with a force wrench, and the reed raw material, the delignified reed sample, and the toughened modified reed sample were cut into $3-\mathrm{cm}$ slides and placed on a fixture. The test was performed by applying a dynamic sine wave bending load in the middle of the sliced specimen through the loading axis.

In Eq. $4, E^{\prime}$ is the storage modulus ( $\mathrm{MPa}$ ), which reflects the energy stored in the material due to elastic deformation during the deformation process, and characterizes the stiffness of the material; $E^{\prime \prime}$ is the loss modulus (MPa), which reflects the material's viscosity change during the deformation. The energy consumed in the form of heat is known as damping. The damping of materials is also often expressed by the tangent $\tan \delta$ of the phase difference between stress and strain, which is called mechanical internal loss, and its value is equal to the ratio of the loss modulus of the material to the storage modulus, which is expressed in Eq. 5:

$$
\tan \delta=\frac{E^{\prime \prime}}{E^{\prime}}
$$

\section{RESULTS AND DISCUSSION}

\section{Morphological Analysis}

The morphologies of the outer surface of the reed straw section without treatment, after delignification, and after toughening modification are shown in Fig. 2.
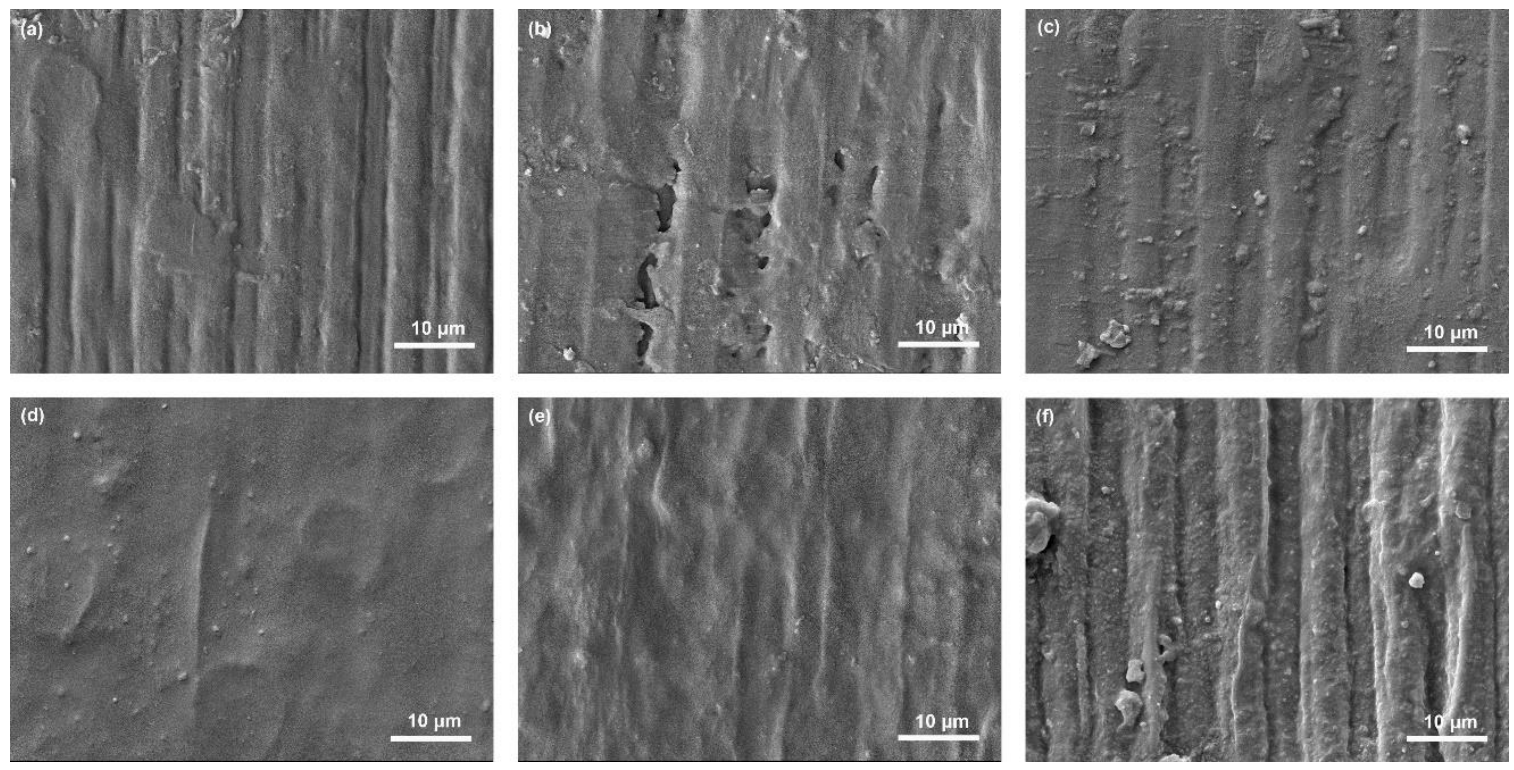

Fig. 2. Morphology of the outer surface of reed straw sections untreated, after delignification, and after being toughened: (a) the untreated straw; (b) the straw after delignification; (c) the straw after being toughened by PEG 600; (d) the straw after being toughened by PEG 1000; (e) the straw after being toughened by PEG 2000; (f) the straw after being toughened by PEG 4000

The wax coating uniformly covered the outer surface of the reed stalk without treatment. Fewer micropores and little internal structure of the reed can also be found (HuiDong et al. 2010; Jin et al. 2016) (Fig. 2(a)). The surface of the reed stalk became rough and damaged after delignification (Fig. 2(b)). 
This is because the wax on the surface of the reed is a fatty substance composed of fatty alcohols and higher fatty acids, which can be oxidized by oxidants. The decomposition product of chlorine dioxide (sodium chlorite) can be reacted with lignin, which may break the wax in the reed and create conditions for the penetration and diffusion of polyethylene glycol with different molecular weights. From Fig. 2(c) to Fig. 2(e), it was shown that the surface of the modified reed became smoother. The permeation of PEG may block the hole of the reed. This demonstrated the penetration or organic binding effect of PEG. After modification by PEG 4000 (Fig. 2(f)), the reed surface became rougher and the inner cell structure appeared, which indicated that the modification of PEG 4000 destroyed the surface waxy layer.
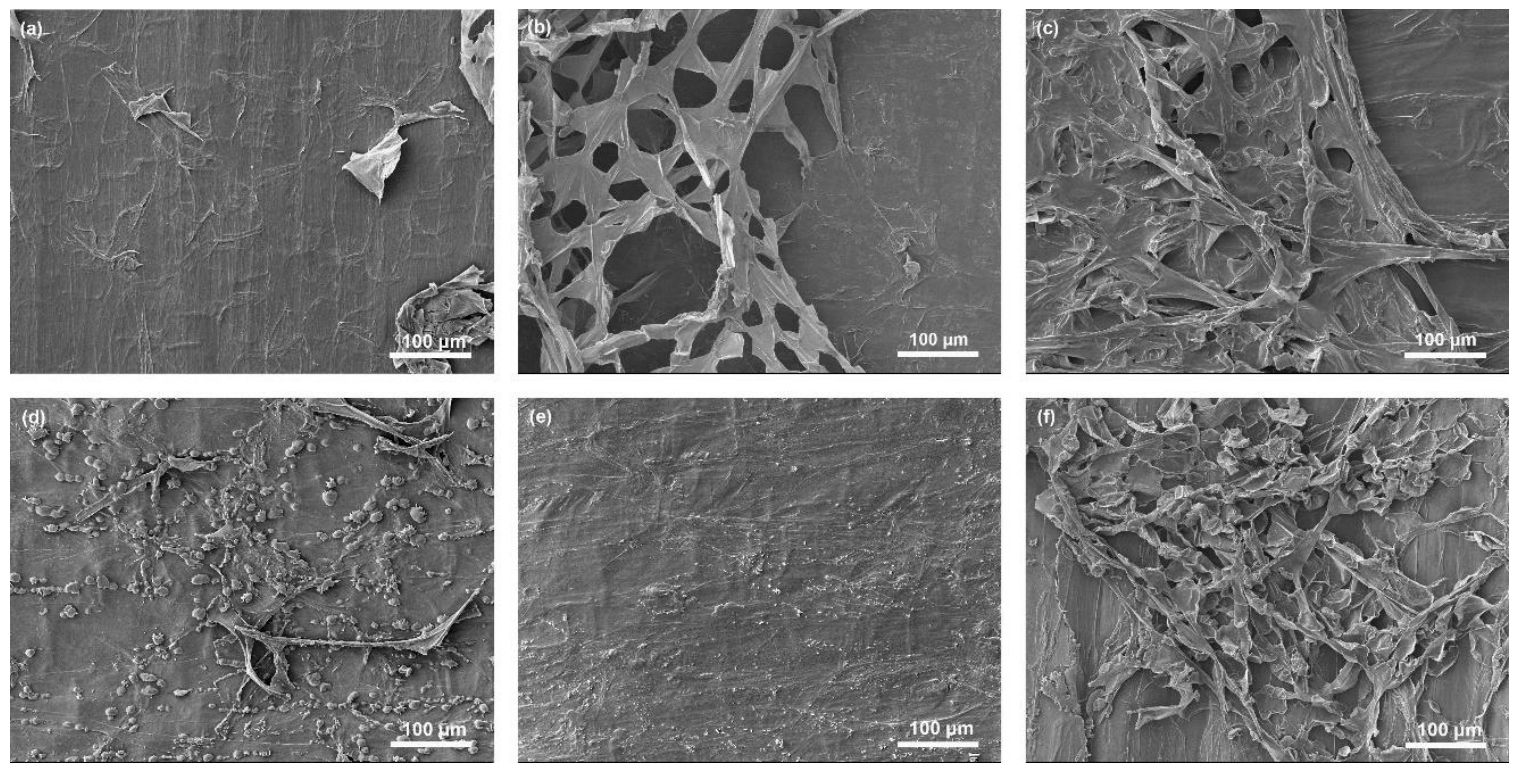

Fig. 3. Morphology of the inner surface of reed straw sections untreated, after delignification, and after being toughened: (a) the untreated straw; (b) the straw after delignification; (c) the straw after being toughened by PEG 600; (d) the straw after being toughened by PEG 1000; (e) the straw after being toughened by PEG 2000; (f) the straw after being toughened by PEG 4000

The inner surface of the reed is mainly composed of thin-walled cells, and the fiber skeleton is clearly visible (Fig. 3(a)). The film of the reed stalk was peeled off after delignification (Fig. 3(b)). The fibrous cell structure was noticeably exposed. The impregnation and penetration of the PEG into the reed stalk cell can be inferred. The surface cell shedding of the reed stalk modified by PEG 600 (Fig. 3(c)) was more obvious than that of the delignified samples (Fig. 3(b)).

Compared with the unmodified sample, the samples after modification (Fig. 3(d) and Fig. 3(e)) showed a rougher inner surface, and the film was less detached. The samples modified by PEG 1000 exhibited obvious particles in the surface (Fig. 3(f)). The film shedding phenomenon on the inner surface of the reed modified by PEG 4000 was mostly obvious, which may also lead to the loss of the mechanical properties of the reed stalk.

It can be seen from Fig. 4(a) that the cross-section of the reed stalk was mainly composed of ring-shaped ducts and thin-walled cells. In comparison with Fig. 4(b), the cell wall of the reed stalk became thinner and smoother after delignification. Figure 4(c) shows that the shape of the thin-walled cells modified by PEG 600 became round, and the cell 
wall became thickened and stronger. The cell wall collapsed (Fig. 4(d)) and the cell in Fig. 4(e) became larger and the cell wall deformed. This may weaken the cell wall support and the toughness of fibers. The most obvious changes of cell wall occurred in the samples that were modified by PEG 4000. The cell wall completely lost its support and was severely deformed. This also indicated that PEG 4000 had the greatest effect on the mechanical properties of reeds.
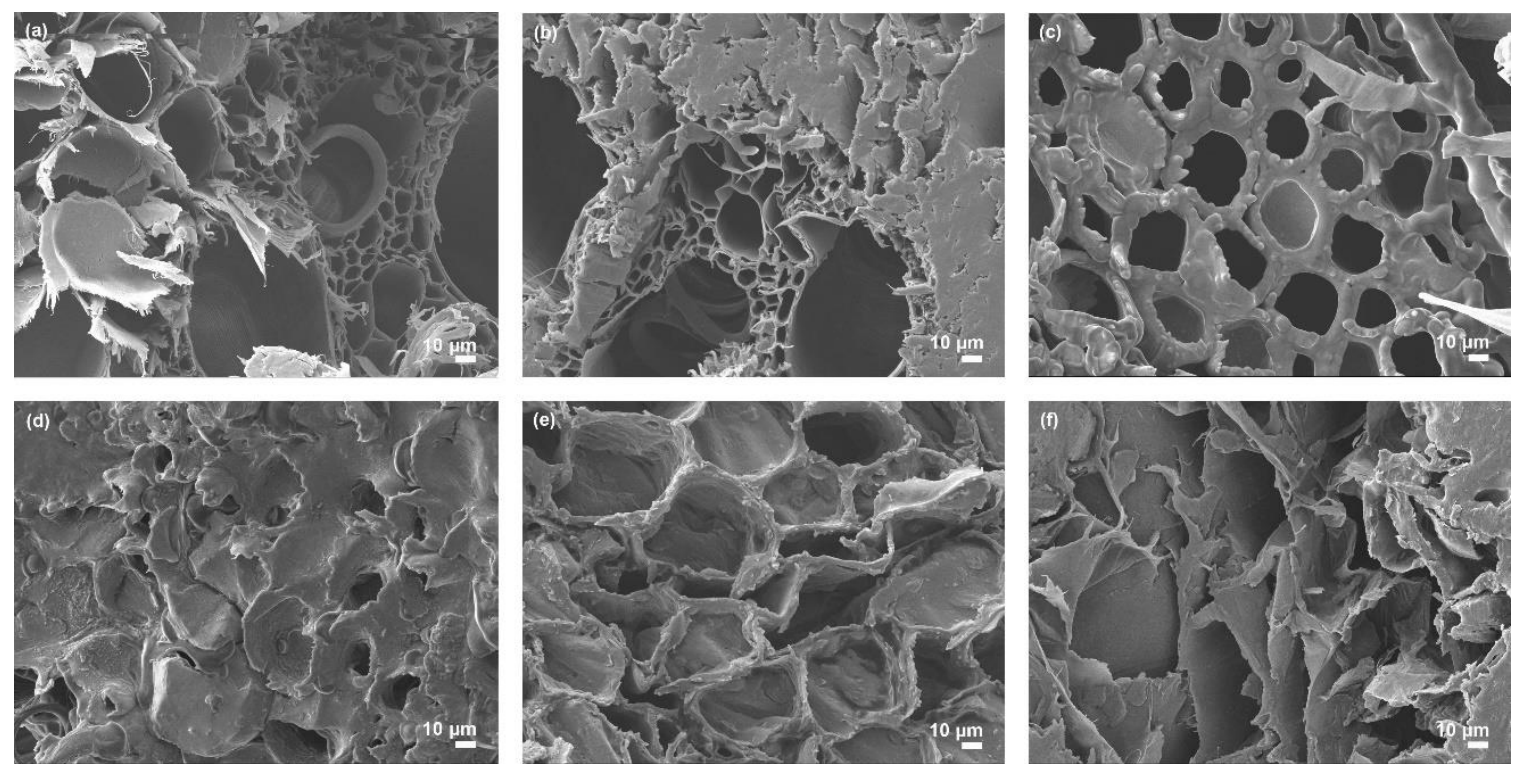

Fig. 4. Morphology of the cross-section of reed straw sections untreated, after delignification, and after toughened conditions: (a) the untreated straw; (b) the straw after delignification; (c) the straw after being toughened by PEG 600; (d) the straw after being toughened by PEG 1000; (e) the straw after being toughened by PEG 2000; $(f)$ the straw after being toughened by PEG 4000

\section{FT-IR Characterization}

Figure 5 shows the infrared absorption spectra of the reed samples before and after delignification, and those delignified samples after modification treatments with PEG. No new peak was generated in the infrared absorption spectrum after the modification processes. Compared with the original material, all absorption peaks of the reed stalks decreased after delignification. The peak at $1113 \mathrm{~cm}^{-1}$ was attributed to the CO-OR stretching vibration of hemicellulose and the $\mathrm{C}-\mathrm{O}$ stretching vibration of phenolic hydroxyl groups in lignin. The $\mathrm{C}-\mathrm{O}$ absorption peak decreased after delignification treatment, indicating that the oxidation of sodium chlorite caused the removal of lignin. The absorption intensity of the hydroxy $(\mathrm{OH})$ peak at $3420 \mathrm{~cm}^{-1}$ increased noticeable after modification with PEG. This is the characteristic peak of hydrogen bond $(-\mathrm{OH})$ tensile vibration (Sang et al. 2005; Široký et al. 2010). The largest absorption peak was found when the sample was modified with PEG 600, followed by PEG 1000, PEG 2000, and PEG 4000. It indicated that the content of PEG was increased in the reed samples after modification, and it further illustrated that the modifier penetrated well into the reed stalk. The absorption peak at $2888 \mathrm{~cm}^{-1}$ represents the stretching vibration of methylene $\left(-\mathrm{CH}_{2}\right)$ (Zhang et al. 2015). The intensity of the methylene absorption peak decreased after PEG 
modification and decreased with the increase in PEG molecular weight. It indicated the increase in the number of substituents on the methylene.

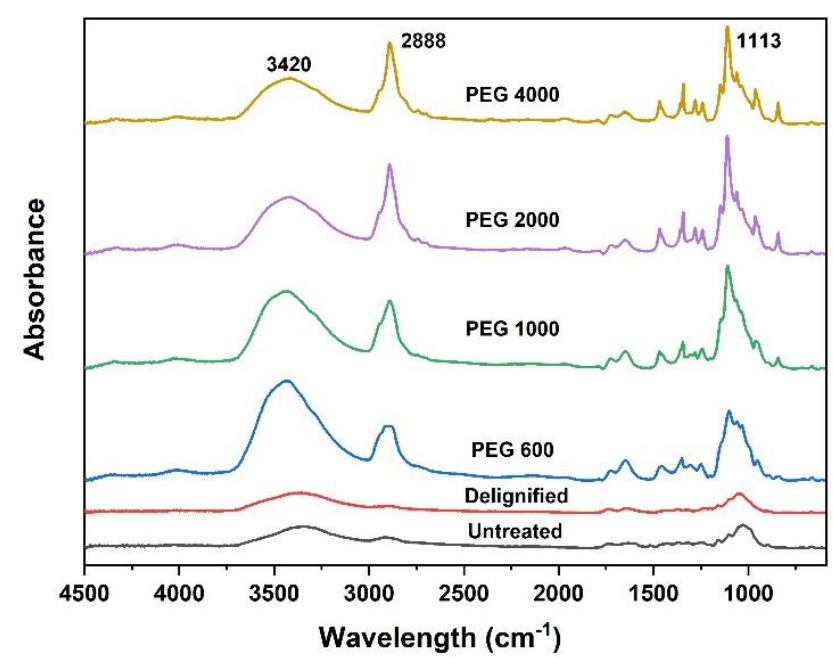

Fig. 5. Infrared absorption spectra of reed stalks before and after modification by polyethylene glycols with different molecular weights

PEG 1000 and PEG 2000 entered the reed stalk more easily and reacted with the chemical components in the reed. The PEG attached more easily in the reed cell, and then affected its microstructure and mechanical properties.

\section{X-ray Diffraction Analysis}

Results of XRD analysis are shown in Fig. 6.

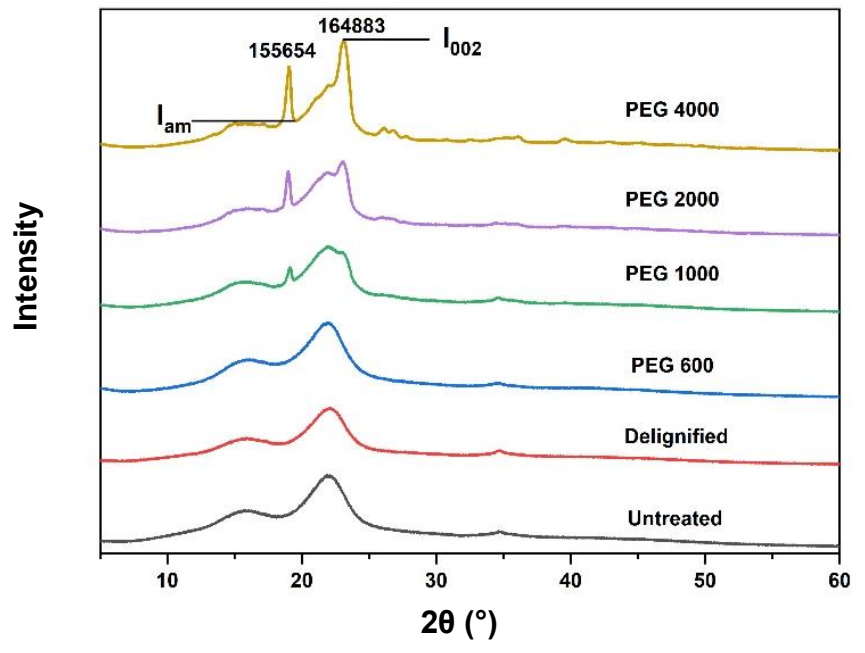

Fig. 6. XRD patterns of reed stalks before and after modification with different molecular weight polyethylene glycols

The crystallinity of reed stalks before and after modification using PEG with different molecular weight were calculated according to Eq. 1 and the data is shown in Table 1. A major peak and a secondary peak at $22^{\circ}$ and $18^{\circ}$ were noted for the reed stalk 
before and after delignification, respectively. These peaks were considered to represent the typical cellulose-I structure (Mostafa 1958). It indicated that the method of delignification had little effect on the crystalline region of the inner cellulose and the distance between the crystalline layers.

Table 1. XRD Data of Reed Stalks Before and After Modification with Different Molecular Weight Polyethylene Glycols

\begin{tabular}{|c|c|c|c|}
\hline Approach & $I_{0.02}$ & $l_{\mathrm{am}}$ & Crystallinity (\%) \\
\hline PEG 4000 & 164883 & 155654 & 5.6 \\
\hline PEG 2000 & 125774 & 112383 & 10.6 \\
\hline PEG 1000 & 98699 & 80164 & 10.7 \\
\hline PEG 600 & 74233 & 61385 & 17.3 \\
\hline Delignified & 46912 & 35049 & 25.3 \\
\hline Untreated & 20056 & 12667 & 36.8 \\
\hline
\end{tabular}

Cellulose consists of a crystalline region and a non-crystalline region, whereas hemicellulose and lignin are amorphous (Sun et al. 2015). Cellulose crystallinity is the key factor determining the mechanical and physical properties of materials. Cellulose crystallinity refers to the percentage of the cellulose crystalline region in the entire cellulose. As the crystallinity increases, the tensile strength, and elastic modulus of the fiber increase. The fiber crystallinity of the untreated reed stalk was $36.8 \%$. The cellulose crystallinity decreased with the increase of the molecular weight of PEG, which indicated that the penetration of polyethylene glycol into the reed stalk had less effect on the cellulose crystallinity.

\section{Blending Strength}

PEG as a substitute for water can be maintained in cell walls even under equilibrium conditions in dry environments and under mechanical loads (Bjurhager et al. 2010). Lignin and hemicellulose in reeds are amorphous structures, while cellulose has both crystalline (ordered) and amorphous regions. Cellulose and hemicellulose are hydrophilic, while lignin is less hydrophilic than hemicellulose. The cellulose tissue is in the crystalline and noncrystalline regions. From a mechanical point of view, these components and hemicellulose structure are responsible for the tensile elastic behavior. Lignin and hemicellulose contribute not only to the viscoelasticity of matrix but also to the plastic deformation beyond the proportional limit. Water causes the cell wall to swell and soften, which will significantly influence the deformation mechanism of the material and ultimately influence the strength and structural integrity of the material on a larger scale (De Magistris and Salmén 2006, 2008).

The elastic modulus of reed stalks modified using PEG with different molecular weights is shown in Fig. 6. The elastic modulus of the reed stalk decreased after modification. The highest value was obtained when the reed was modified by PEG 600 . This was in accord with the results in SEM analysis. The elastic modulus of the reed stalk then decreased with the increase in PEG molecular weight under the same immersion condition $(24 \mathrm{~h})$. The smallest elastic modulus (133.3 MPa) was obtained when the samples were treated with PEG 2000.The elastic modulus reflects the elasticity of the material and refers to the ability to resist elastic deformation after being stressed. A higher elastic modulus results in a tendency to resist elastic deformation. The elastic modulus of the modified reeds with PEG 1000 and PEG 2000 was small, which indicated the increase in 
the toughness of the reed stalks. The hydroxyl groups in polyethylene glycol may be bound with the hydrogen bonds in cellulose and lignin, and stronger bonding develops to resist deformation, resulting in the increase in the bending properties of the material. It can be concluded from the study that polyethylene glycol modifiers with molecular weights of 1000 and 2000 were most suitable for toughening of the reed stalk.

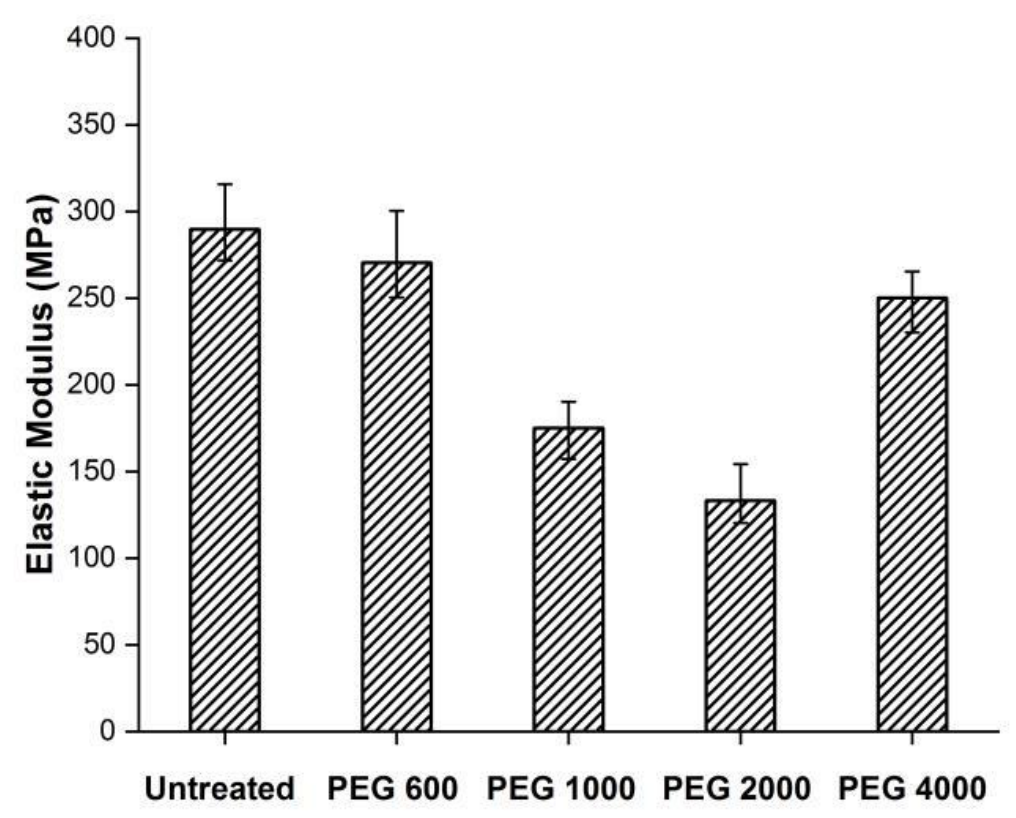

Fig. 7. Experimental results of elastic modulus of polyethylene glycol modified with different molecular weights

\section{Thickness swelling Analysis}

The thickness swelling values of the specimens before and after modification by polyethylene glycol with different molecular weights are shown in Fig. 8.

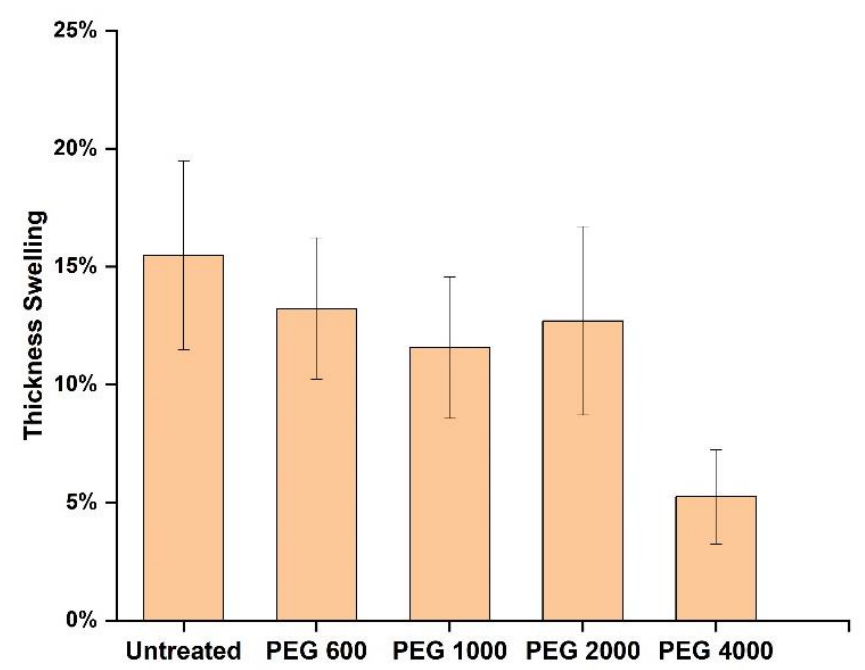

Fig. 8. Thickness swelling results 
The thickness swelling of each sample was calculated and the average value of each test point was taken. The results showed that the thickness swelling of unmodified reed was $15.5 \%$. The thickness swelling of the modified samples by PEG with different molecular weight decreased. The decrease in thickness swelling indicated that PEG penetrated the reed cell wall. The water resistance increased with the increase in PEG molecular weight. The PEG molecular penetrated into cell wall and displaced hydrogen bonds joining cellulosic surfaces with each other. It decreased the hygroscopic of the samples. Polyethylene glycol can react with hydroxyl groups as a dehydration reaction. It can increase the toughness of reed.

\section{Dynamic Mechanical Tests}

The temperature spectrum of the dynamic mechanical properties of reed stalks is a measurement of the change of dynamic mechanical properties of reed materials with temperature at a fixed frequency. Temperature scanning tests on reed stalks can be used to obtain the change curves of storage modulus $E^{\prime}$, loss modulus $E^{\prime \prime}$, and phase angle tangent value $\tan \delta$ with temperature, as shown in Fig. 9. The storage modulus $E^{\prime}$ gradually decreased as the temperature increased from $-20{ }^{\circ} \mathrm{C}$ to $260{ }^{\circ} \mathrm{C}$. It can be attributed to the relatively low energy of molecule movement at the lower temperature, and only some small size units (side chain, branch chain, main chain or functional group on branch chain) of the moleculars can move. As a result, the storage modulus value of reed stalk was higher at low temperature. With the increase in the test temperature, the thermal motion energy of moleculars tends to rise, leading to the movement of the molecular chain segments or part of the chain segments. Therefore, the value of storage modulus tends to decrease. Compared with the untreated samples, the change tendency of storage modulus $E^{\prime}$ was similar when the samples were modified at different temperatures. The storage modulus $E^{\prime}$ decreased sharply from the temperature of $220{ }^{\circ} \mathrm{C}$; however, the storage modulus $E^{\prime}$ of samples modified by PEG 1000 and 2000 was higher than that of the untreated samples. It indicated that the storage modulus $E^{\prime}$ increased with modification using PEG 1000 and PEG 2000, which indicated the increase in bending strength. This result corresponded with the change of the elastic modulus in Fig. 7. The relative storage modulus of some treated materials were higher than that of untreated materials within the test temperature range. The reason may be due to the degradation of the non-crystalline polysaccharide during the modified treatment of reed, and the degradation product furfural enhanced the cross-linking reaction of lignin, leading to the increase in the stiffness of reed, and thus the increase in the storage modulus of the treated material (Jalaludin et al. 2010). The storage modulus $E^{\prime}$ showed a gradually declining trend with the increase in the measurement temperature, while the loss modulus $E^{\prime \prime}$ first showed a trend of increasing and then decreasing. The most obvious changes in modulus occurred in the samples modified by PEG 1000 and PEG 2000. This indicated that the penetration of PEG 1000 and PEG 2000 modifiers increased the storage modulus of reed stalks, which also caused a large loss in the energy. The amorphous cellulose, hemicellulose, and lignin in the reed would undergo glass transition (i.e., soften) when the reed was heated to the glass transition temperature $\left(T_{\mathrm{g}}\right)$. The change in the $T_{\mathrm{g}}$ value has a greater relationship with the flexibility of the polymer segment. Generally, a lower $T_{\mathrm{g}}$ value is attributed to a higher flexibility and of the segment, while a higher $T_{\mathrm{g}}$ value resulted in a higher rigidity of the segment. According to ASTM E164013 (2018), the temperature corresponding to the $\tan \delta$ peak is defined as $T_{\mathrm{g}}$. 

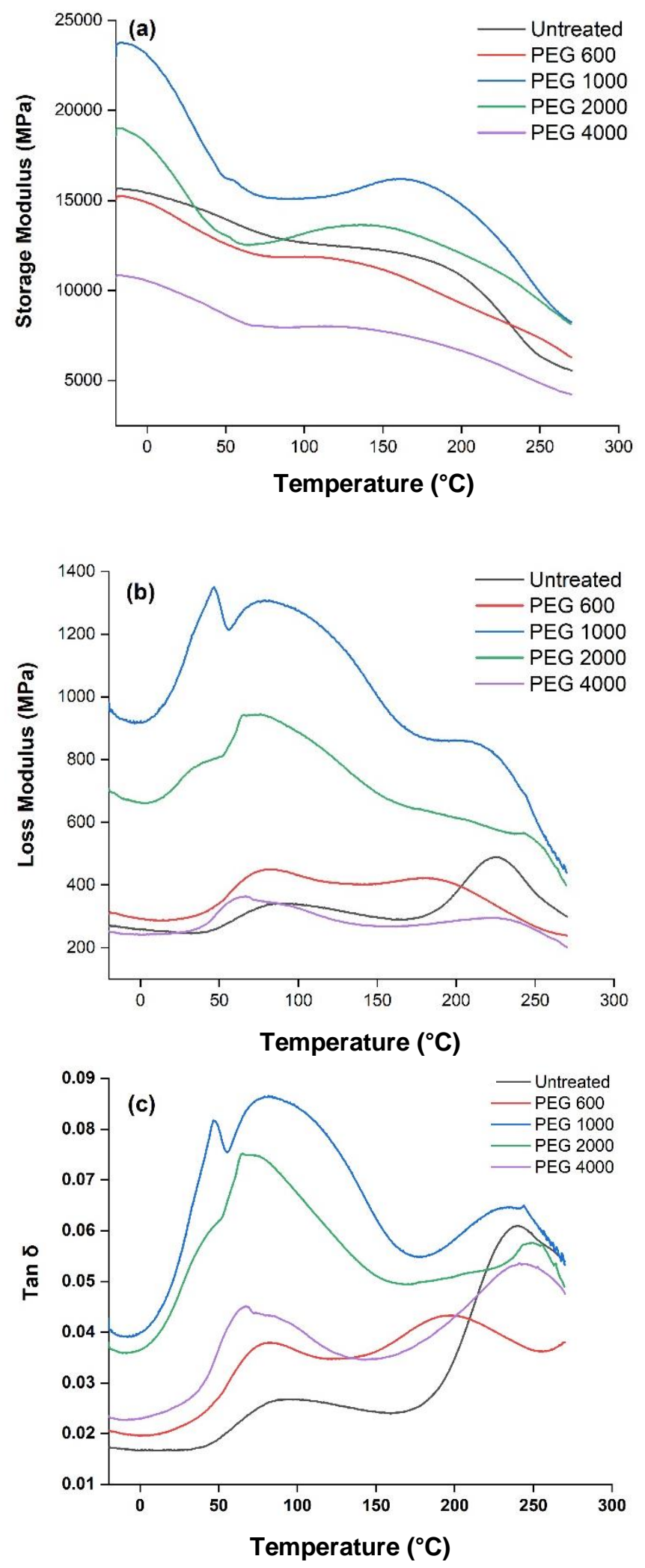

Fig. 9. Relationship between storage modulus (a), loss modulus (b), and phase angle tangent value (c) of reed stalks modified with different molecular weights and temperature 
From the relationship between phase tangent and temperature, it can be seen that the temperature corresponding to the $\tan \delta$ peak of the PEG 1000 and PEG 2000 modified samples was approximately $40^{\circ} \mathrm{C}$, while the $\tan \delta$ peak of the PEG 600 and PEG 4000 modified samples corresponded to a temperature that was higher than $60^{\circ} \mathrm{C}$. This indicated that the reed stalks modified with PEG 1000 and PEG 2000 showed greater flexibility.

\section{CONCLUSIONS}

1. To increase the toughness of the reed stalk, lignin was partially removed from the reed stalk using sodium chlorite $\left(\mathrm{NaClO}_{2}\right)$, and $\mathrm{PEG}$ with different molecular weights were impregnated into the delignified reed samples. PEG molecular entered into cell wall and reacted with cell wall components. The bending strength of the reed stalk increased after the modification. The crystallinity increased after modification, which was positive on the increase in tensile strength, and elastic modulus of the fiber.

2. The removal of lignin and PEG impregnation were positive in bending property. The modified reed stalk showed a rougher inner surface, and the film was less detached. The cell wall of the reed stalk became thinner and smoother after delignification. The shape of the thin-walled cells modified by PEG became round, and the cell wall became thickened and stronger. The storage modulus $E$ ' increased with modification using PEG 1000 and PEG 2000, which indicated the increase in bending strength. The delignified reed stalks reinforced with PEG 1000 or PEG 2000 showed a lower elastic modulus, $T_{\mathrm{g}}$ value, greater toughness and better dimensional stability. The smallest elastic modulus (133.3 MPa) was obtained when the samples were treated with PEG 2000.

3. The water resistant of the PEG modified reed stalks increased with the increase of PEG molecular weight. It decreased the hygroscopic of the samples. The samples modified with PEG 4000 showed the best water resistant and dimensional stability. The work provided a certain theoretical basis for the characterization of the toughening effect of modified reeds in the later stage.

\section{ACKNOWLEDGEMENTS}

51572028).

This research was funded by National Natural Science Foundation of China (No.

\section{REFERENCES CITED}

Ahlgren, P. A., and Goring, D. (2011). "Removal of wood components during chlorite delignification of black spruce," Canadian Journal of Chemistry 49(8), 1272-1275.

DOI: $10.1139 / \mathrm{v} 71-207$

ASTM E1640-13 (2018). "Standard test method for assignment of the glass transition temperature by dynamic mechanical analysis," ASTM International, West Conshohocken, PA, USA.

Bjurhager, I., Ljungdahl, J., Wallstrom, L., Gamstedt, E. K., and Berglund, L. A. (2010).

"Towards improved understanding of PEG-impregnated waterlogged archaeological 
wood: A model study on recent oak," Holzforschung 64(2), 243-250. DOI: 10.1515/HF.2010.024

Chaouch, M., Pétrissans, M., Pétrissans, A., and Gérardin, P. (2010). "Use of wood elemental composition to predict heat treatment intensity and decay resistance of different softwood and hardwood species," Polymer Degradation and Stability 95(12), 2255-2259. DOI: 10.1016/j.polymdegradstab.2010.09.010

De Magistris, F, and Salmén, L. (2006). "Mechanical behaviour of wet wood in sequences of compression and combined compression and shear," Nord. Pulp Paper Res. J. 21(2), 231-236. DOI: 10.3183/NPPRJ-2006-21-02-p231-236

De Magistris, F., and Salmén, L. (2008). "Finite element modelling of wood cell deformation transverse to the fibre axis," Nord. Pulp Paper Res. J. 23(2), 240-246. DOI: 10.3183/NPPRJ-2008-23-02-p240-246

Devnani, G. L., and Sinha, S. (2019). "Epoxy-based composites reinforced with African teff straw (Eragrostis tef) for lightweight applications," Polymers and Polymer Composites 27(11), 189-200. DOI: 10.1177/0967391118822269

Engelund, E. T., and Salmen, L. (2012). "Tensile creep and recovery of Norway spruce influenced by temperature and moisture," Holzforschung 66(8), 959-965. DOI: 10.1515/hf-2011-0172

Hamada, J., Pétrissans, A., Mothe, F., Ruelle, J., Pétrissans, M., and Gérardin, P. (2016). "Variations in the natural density of European oak wood affect thermal degradation during thermal modification," Annals of Forest Science 73(2), 277-286. DOI: 10.1007/s13595-015-0499-0

Havimo, M. (2009). "A literature-based study on the loss tangent of wood in connection with mechanical pulping," Wood Science and Technology 43(7), Article number 627. DOI: $10.1007 / \mathrm{s} 00226-009-0271-4$

Hazarika, A., Mandal, M., and Maji, T. K. (2014). "Dynamic mechanical analysis, biodegradability and thermal stability of wood polymer nanocomposites," Composites Part B: Engineering 60(568-576). DOI: 10.1016/j.compositesb.2013.12.046

Hui-Dong, L. I., Peng, Z. H., Kang, J., Zhang, D. W., Wang, N. Q., and Zhou, J. H. (2010). "The research of the mechanism of biosorption heavy metal of Cr (VI) with trichoderma," Acta Laser Biology Sinica 19(3), 353-357. DOI: 10.3969/j.issn.10077146.2010.03.012

Ismail, M. R., Yassen, A. A. M., and Afify, M. S. (2011). "Mechanical properties of rice straw fiber-reinforced polymer composites," Fibers and Polymers 12(5), 648-656. DOI: $10.1007 / \mathrm{s} 12221-011-0648-5$

Jacob, J. M., Francis, B., Thomas, S., and Varughese, K. T. (2006). "Dynamical mechanical analysis of sisal/oil palm hybrid fiber-reinforced natural rubber composites," Polymer Composites 27(6), 671-680. DOI: 10.1002/pc.20250

Jain, J., Jain, S., and Sinha, S. (2019). "Characterization and thermal kinetic analysis of pineapple leaf fibers and their reinforcement in epoxy," Journal of Elastomers and Plastics 51(3), 224-243. DOI: 10.1177/0095244318783024

Jalaludin, Z., Hill, C. A. S., Xie, Y.-J., Samsi, H. W., Husain, H., Awang, K., and Curling, S. F. (2010). "Analysis of the water vapour sorption isotherms of thermally modified acacia and sesendok," Wood Material Science \& Engineering 5(3-4), 194203. DOI: $10.1080 / 17480272.2010 .503940$

Jin, F., Jiang, Z., and Wu, Q. (2016). "Creep behavior of wood plasticized by moisture and temperature," BioResources 11(1), 827-838. DOI: 10.15376/biores.11.1.827-838 
Kaboorani, A., and Blanchet, P. (2014). "Determining the linear viscoelastic region of sugar maple wood by dynamic mechanical analysis," BioResources 9(3), 4392-4409. DOI: $10.15376 /$ biores.9.3.4392-4409

Meints, T., Hansmann, C., and Gindl-Altmutter, W. (2018). "Suitability of different variants of polyethylene glycol impregnation for the dimensional stabilization of oak wood," Polymers (Basel) 10(1), Article number 81. DOI: 10.3390/polym10010081

Mittal, V., and Sinha, S. (2017). "Study the effect of fiber loading and alkali treatment on the mechanical and water absorption properties of wheat straw fiber-reinforced epoxy composites," Science and Engineering of Composite Materials 24(5), 731-738. DOI: 10.1515/secm-2015-0441

Mostafa, M. A. K. (1958). "Degradation of addition polymers by ultrasonic waves. III. Experimental," Journal of Polymer Science Part A Polymer Chemistry 28(102), 499518. DOI: 10.1002/pol.1958.1202811803.

Rials, T. G., and Glasser, W. G. (1984). "Characterizing wood components as network polymers by dynamic mechanical analysis," Wood and Fiber Science 16(4), 537-542.

Sang, Y. O., Yoo, D. I., Shen, Y., and Seo, G. (2005). "FTIR analysis of cellulose treated with sodium hydroxide and carbon dioxide," Carbohydrate Research 340(3), 417428. DOI: 10.1016/j.carres.2004.11.027

Segal, L., Creely, J. J., Martin, Jr, A. E., and Conrad, C. M. (1959). "An empirical method for estimating the degree of crystallinity of native cellulose using the X-ray diffractometer," Textile Research Journal 29(10), 786-794. DOI: 10.1177/004051755902901003

Široký, J., Blackburn, R. S., Bechtold, T., Taylor, J., and White, P. (2010). "Attenuated total reflectance Fourier-transform Infrared spectroscopy analysis of crystallinity changes in lyocell following continuous treatment with sodium hydroxide," Cellulose 17(1), 103-115. DOI: 10.1007/s10570-009-9378-x

Stamm, A. J. (1964). "Factors affecting the bulking and dimensional stabilization of wood with polyethylene glycols," Forest Products Journal 14, 403-408.

Stamm, A. J., and Tarkow, H. (1947). "Dimensional stabilization of wood," The Journal of Physical Chemistry 51(2), 493-505. DOI: 10.1021/j150452a016

Sun, S.-N., Sun, S.-L., Cao, X.-F., and Sun, R.-C. (2015). "The role of pretreatment in improving the enzymatic hydrolysis of lignocellulosic materials," Bioresource Technology 199, 49-58. DOI: 10.1016/j.biortech.2015.08.061

Yamaguchi, T., Ishimaru, Y., and Urakami, H. (1999). "Effect of temperature on dimensional stability of wood with polyethylene glycol. I. Bulking effect," Mokuzai Gakkaishi 45(6), 434-440.

Zou, Y., Huda, S., and Yang, Y. (2010). "Lightweight composites from long wheat straw and polypropylene web," Bioresource Technology 101(6), 2026-2033. DOI: 10.1016/j.biortech.2009.10.042

Zhang, H.-H., Ming, R.-H., Yang, G.-S., Li, Y.-Z., Li, Q., and Shao, H.-L. (2015). "Influence of alkali treatment on flax fiber for use as reinforcements in polylactide stereocomplex composites," Polymer Engineering and Science 55, 2553-2558.

Article submitted: February 25, 2020; Peer review completed: July 4, 2020; Revised version received and accepted: July 26, 2020; Published: July 31, 2020.

DOI: $10.15376 /$ biores. 15.3.7127-7142 